\title{
MAGE-A expression clusters and antineoplastic treatment in head and neck cancer
}

\author{
STEFAN HARTMANN, TILL J. MEYER, ROMAN C. BRANDS, IMME R. HAUBITZ, CHRISTIAN LINZ, \\ AXEL SEHER, ALEXANDER C. KÜBLER and URS D.A. MÜLLER-RICHTER
}

Department of Oral and Maxillofacial Plastic Surgery, University Hospital of Würzburg, D-97070 Würzburg, Germany

Received February 9, 2015; Accepted April 7, 2015

DOI: $10.3892 / \mathrm{ijmm} .2015 .2174$

\begin{abstract}
The nonsurgical treatment of head and neck squamous cell carcinoma (HNSCC) usually consists of radiation and chemotherapy. In general, the treatment efficacy of chemotherapy in head and neck cancer is limited. Apart from the placenta, testis and fetal keratinocytes, melanoma-associated antigens-A (MAGE-A) are only found in malignancies. Even though their molecular role remains unclear, several subgroups have been found to contribute to resistance to different chemotherapeutic agents. In the present study, established human squamous cell carcinoma cell lines were incubated with various concentrations of cisplatin, 5-fluorouracil, paclitaxel, docetaxel, cetuximab and panitumumab for 5, 10, 20 and $40 \mathrm{~h}$. The treatment efficacy was measured dynamically by real-time cell analysis (RTCA). In addition, we determined the expression of all known MAGE-A subgroups (MAGE-A1 to MAGE-A12, excluding pseudogene MAGE-A7) by reverse transcription quantitative polymerase chain reaction. Of note, one cell line showed only a marginal expression of MAGE-A antigens, whereas another cell line showed a distinct expression of almost all the MAGE-A subgroups. The expression pattern varied in the other cell lines. MAGE-A4 was the most highly expressed of all the subgroups, and MAGE-A8 could not be detected. With the exception of MAGE-A6, -A8, -A9 and -A10, the expression levels differed significantly between the cell lines. Factor analysis suggested simplifying the MAGE-A expression level into two groups. Spearman's rank correlation revealed a significant association between MAGE-A expression and treatment efficacy for $20.8 \%(25 / 120)$ of the experiments. In $100 \%$ of these cases (25/25), Spearman's Rho revealed a positive correlation between clustered MAGE-A expression and poor treatment efficacy. Our data highlight the fact that
\end{abstract}

Correspondence to: Dr Stefan Hartmann, Department of Oral and Maxillofacial Plastic Surgery, University Hospital of Würzburg, Pleicherwall 2, D-97070 Würzburg, Germany

E-mail: hartmann_s2@ukw.de

Key words: melanoma-associated antigens-A, tumor antigen, chemotherapy, head and neck cancer, head and neck squamous cell carcinoma higher a MAGE-A expression correlates with a poorer outcome of antineoplastic treatment. Clustered MAGE-A expression analysis may help to identify patients who are at a higher risk of antineoplastic treatment failure.

\section{Introduction}

The treatment of head and neck cancer remains challenging. Due to the high rate of locally advanced and metastatic tumors, intensified adjuvant treatment regimes, including radiotherapy and chemotherapy, are performed. However, local recurrence is a common occurrence, and the cumulative 5-year overall survival is approximately $50 \%$ (1). In addition to TNM staging and histological grading, molecular markers may aid in the identification of high-risk patients. Melanoma-associated antigens-A (MAGE-A) proteins belong to the very large family of cancer/testis antigens (CTA) (2). With the exception of the placenta, testis and fetal keratinocytes, MAGE-A expression is restricted to malignant tissues. In general, MAGE-A expression has been reported in malignant melanoma (3), breast cancer (4), lung cancer (5), urothelial carcinoma (6), colorectal carcinoma (7), hepatocellular carcinoma (8) and head and neck cancer (9). Typically, the different subgroups are co-expressed, but there is no unique expression pattern for specific tumor entities (10). Remarkably, MAGE-A expression has been found in oral carcinoma in situ and leukoplakia with dysplasia, but has not been detected in oral ulcers, oral lichen planus and leukoplakia without dysplasia (11). Recently, Han et al reported that a high MAGE-A9 expression is a poor prognostic marker in laryngeal squamous cell carcinoma (12). Of note, in their study, MAGE-A9 expression did not correlate with the TNM status, but a highly significant correlation was observed with grading and overall survival, indicating that the MAGE-A9 expression status may thus be another way of identifying high-risk patients, apart from TNM. Our group previously demonstrated a correlation between the treatment efficacy of several drugs and the expression of certain MAGE-A subgroups $(13,14)$. This correlation may be mediated, at least in part, by MAGE-induced p53-inhibition (15) and/or MAGE-associated expression of taxol resistance-associated gene-3 (TRAG-3) (16). Additionally, MAGE-A3 expression has been shown to contribute to an increased tumor size and the size of metastatic foci in an animal xenograft model of thyroid cancer (17). As antigens, MAGE proteins can be recognized 
by T-cells and thus lead to immune activation. This property makes them interesting players in terms of tumor vaccination. For example, in non-small cell lung cancer (NSCLC) patients, MAGE-A3 vaccine has been shown to contribute to the reduction of recurrence rates compared with the control group (18).

This study was designed to evaluate the prognostic value of all known MAGE-A antigens in terms of response to chemotherapy. As the evaluation of the distinct functional role of all MAGE-A antigens is almost unmanageable, the total and clustered MAGE-A expression in the context of chemoresistance was examined.

\section{Materials and methods}

Cell lines. We used cell lines that were originally established (Table I) at the Cancer Institute of the University of Pittsburgh (19) and used in our previous studies $(13,14,20)$. As previously described, the cells were cultured in a humidified atmosphere of $5 \% \mathrm{CO}_{2} / 95 \%$ air at $37^{\circ} \mathrm{C}$ and fed 2 to 3 times/week $(14,20)$.

Drugs. For the antineoplastic treatment of the cell lines, we selected agents that are widely used in different protocols for induction or for neoadjuvant or adjuvant chemotherapy in head and neck cancer. Cisplatin was purchased from Teva (Radebeul, Germany) and 5-fluorouracil was purchased from Medac (Hamburg, Germany). Paclitaxel, docetaxel, cetuximab and panitumumab were provided by the pharmacy of the University Hospital of Würzburg, Germany.

Measurement of cytotoxicity by real-time cell analysis $(R T C A)$. For the determination of cytotoxicity, we used an impedance-based, non-colorimetric and interference-free RTCA system (xCELLigence RTCA SP System; Roche, Mannheim, Germany). Measurement intervals were $30 \mathrm{~min}$. This method is established and has been previously described for cytotoxicity measurement in head and neck cancer cell lines (21). We seeded 10,000 cells/well of each cell line. Following overnight incubation, cisplatin $(25-400 \mu \mathrm{M})$, 5-fluorouracil $(0.75-12 \mathrm{mM})$, docetaxel $(1.56-25 \mathrm{nM})$, paclitaxel $(1.56-25 \mathrm{nM})$, cetuximab $(0.01-100 \mu \mathrm{g} / \mathrm{ml})$ and panitumumab $(0.01-100 \mu \mathrm{g} / \mathrm{ml})$, all dissolved in $20 \mu \mathrm{l}$ Dulbecco's modified Eagle's medium (Life Technologies GmbH/ThermoFisher Scientific, Darmstadt, Germany), were added to the cultures, which were incubated for an additional $40 \mathrm{~h}$. All of the experiments were performed in triplicate, and further evaluations used mean values.

$R N A$ isolation and reverse transcription-quantitative polymerase chain reaction $(R T-q P C R)$. For RNA isolation, the cells were detached from the culture plate and dissolved in TRIzol reagent (Life Technologies GmbH/ThermoFisher Scientific). After repeated centrifugations (at $12,000 \mathrm{x}$ g), the RNA pellet was resolved in $20 \mu \mathrm{l}$ of fully desalinated water. Subsequently, the RNA concentration was determined using a NanoDrop 2000 system (Thermo Fisher Scientific, Waltham, MA, USA). The absorption was measured at a wavelength of $260 \mathrm{~nm}$ and was normalized to the absorption of the fully desalinated water control at the same wavelength. All specimens were diluted to a concentration of $0.2 \mu \mathrm{g} \mathrm{RNA} / \mathrm{ml}$.
In order to remove the DNA contaminants, the RNA was heated up to $42^{\circ} \mathrm{C}$ for 2 min and then chilled on ice. This step was performed in the presence of a gDNA Wipeout Buffer (Qiagen, Venlo, The Netherlands) (Table II). Reverse transcription was carried out by incubation at $42^{\circ} \mathrm{C}$ for $15 \mathrm{~min}$ using a Reverse Transcription kit from QuantiTect (Qiagen). The reverse transcriptase was denatured by heating the sample to $95^{\circ} \mathrm{C}$ for an additional $3 \mathrm{~min}$ (Table III). Polymerase chain reaction was conducted using a QuantiTect SYBR-Green PCR kit 200 (Qiagen) and a C1000 Thermal Cycler (Bio-Rad, Hercules, CA, USA). The protocol and the primers (Qiagen) differ from previous publications by our group and are described in Tables IV-VI. Quantification of expression was calculated relative to $\beta$-actin.

Statistical analysis. For statistical analysis, we used MEDAS software (version 2014; Grund, Margetshöchheim, Germany). Global treatment efficacy is represented as the mean number of viable cells at different drug concentrations and incubation times for all cell lines used. We analyzed the influence of the concentration of each drug at a fixed incubation time with the cell lines as repeats with Friedman 2-way ANOVA by ranks. To evaluate significant differences among MAGE-A subgroup expression, we also used the Friedman test. To simplify expression analysis, factor analysis was performed. Afterwards, the factors were correlated with treatment efficacy by Spearman's rank correlation. Spearman's Rho is the correlation coefficient and expresses the relationship between the two investigated parameters. A Rho value of 1 represents a perfect correlation between both investigated parameters, whereas a Rho value of -1 means a perfect inverse correlation of both parameters. Rho $\geq 0.7$ is considered a high (positive) correlation, whereas Rho values $\leq-0.7$ are considered a high inverse correlation. In our analysis, we correlated the total and the clustered MAGE-A expression with the results of the RTCA experiments. A high number of viable cells is represented by a high RTCA cell index and indicates a low efficacy of the drug used in the experiment. The significance level was set at $\mathrm{p} \leq 0.05$.

\section{Results}

Treatment efficacy. A brief overview on the efficacy of cisplatin incubation is provided in Fig. 1A. Of note, the viable fraction after $5 \mathrm{~h}$ of incubation is higher than the control (25/50/100/200 $\mu \mathrm{M}$ cisplatin). The same effect can be observed after 10 and $20 \mathrm{~h}$ of incubation for concentrations of $25 / 50 / 100 \mu \mathrm{M}$ and $25 / 50 \mu \mathrm{M}$, respectively. After $40 \mathrm{~h}$ of incubation, the viable fraction of all concentrations was $<100 \%$. The effect of cisplatin on the number of viable cells was significantly associated with the incubation time. Based on all incubation intervals, the concentration of cisplatin was not significantly associated with the viable fraction (Table VII).

Fig. 1B provides an overview of the effects of 5-fluorouracil treatment on the cell lines. After an initial increase in the number of viable cells, the viable fraction at all concentrations after $40 \mathrm{~h}$ of incubation is clearly below that of the controls. The effect of 5-fluorouracil on the viable fraction is significantly associated with the incubation time. Like cisplatin, the concentration of 5-fluorouracil is not significantly associated with the viable fraction (Table VII). 
Table I. Name, origin and TNM status of the 5 cell lines used in this study.

\begin{tabular}{lll}
\hline Name & \multicolumn{1}{c}{ Origin } & TNM classification \\
\hline PCI-1 & Laryngeal carcinoma of the glottis of a male patient & pT2N0M0G2 \\
PCI-9 & Primary carcinoma at the base of the tongue of a male patient & pT4N3M0G2 \\
PCI-13 & Male patient diagnosed with oral squamous cell carcinoma of the retromolar triangle & pT4pN1M0G3 \\
PCI-52 & Primary carcinoma of the aryepiglottic fold of a male patient & pT2N0M0G2 \\
PCI-68 & Primary tongue carcinoma of a male patient & pT4N0M0G1
\end{tabular}

Table II. Composition of the gDNA Wipeout Buffer with RNA.

\begin{tabular}{ll}
\hline gDNA Wipeout Buffer, 7X & $2 \mu 1$ \\
Template RNA & $5 \mu 1$ \\
RNase-free water & $7 \mu 1$
\end{tabular}

Table III. Composition of the reverse transcription reaction with purified RNA.

\begin{tabular}{lr} 
Quantiscript reverse transcriptase & $1 \mu 1$ \\
Quantiscript RT buffer, 5X & $4 \mu 1$ \\
RT Primer mix & $1 \mu 1$ \\
Purified RNA & $14 \mu 1$ \\
\hline
\end{tabular}

Table IV. Polymerase chain reaction protocol.

\begin{tabular}{rlll}
\hline $1 \mathrm{x}$ & Polymerase activation & $15 \mathrm{~min}$ & $95^{\circ} \mathrm{C}$ \\
$40 \mathrm{x}$ & Denaturation & $15 \mathrm{sec}$ & $94^{\circ} \mathrm{C}$ \\
& Annealing & $30 \mathrm{sec}$ & $50-60^{\circ} \mathrm{C}$ \\
& Elongation & $30 \mathrm{sec}$ & $72^{\circ} \mathrm{C}$ \\
\hline
\end{tabular}

The characteristics of paclitaxel treatment are shown in Fig. 1C. Cells incubated with 1.56 and $3.12 \mathrm{nM}$ of paclitaxel grew faster than the controls after 5, 10, 20 and $40 \mathrm{~h}$. Higher concentrations of paclitaxel $(6.25,12.5$ and $25 \mathrm{nM})$ lead to a smaller viable fraction than the control cells after 10,20 and $40 \mathrm{~h}$. The effect of paclitaxel on the viable fraction is significantly associated with the incubation time. The concentration of paclitaxel is not significantly associated with the viable fraction (Table VII).

The effects of docetaxel treatment are comparable to those of paclitaxel treatment and are shown in Fig. 1D. With the exception of $1.56 \mathrm{nM}$ of docetaxel after 5 and $10 \mathrm{~h}$, all other concentrations and time intervals showed a smaller viable fraction than the controls. The effect of docetaxel on the viable fraction is significantly associated with the incubation time. The concentration of docetaxel is not significantly associated with the viable fraction (Table VII).

The effects of cetuximab treatment are shown in Fig. 1E. Cetuximab treatment at all concentrations and time intervals led to a higher fraction of viable cells compared with the controls. This effect is time-dependent but not concentrationdependent (Table VII).
Table V. Composition of the polymerase chain reaction mixture.

\begin{tabular}{ll}
\hline SYBR Green Master Mix & $12.5 \mu \mathrm{l}$ \\
QuantiTect Primer assay & $2.75 \mu \mathrm{l}$ \\
cDNA (concentration of $10 \mathrm{ng} / \mu \mathrm{l})$ & $2.5 \mu \mathrm{l}$ \\
Water & $7.25 \mu \mathrm{l}$
\end{tabular}

Table VI. MAGE-A primers.

$\begin{array}{ll}\text { Hs_ACTB_2_SG } & \text { \#QT01680476 } \\ \text { Hs_MAGEA1_2_SG } & \text { \#QT01669430 } \\ \text { Hs_MAGEA2_2_SG } & \text { \#QT01668688 } \\ \text { Hs_MAGEA2B_1_SG } & \text { \#QT01033529 } \\ \text { Hs_MAGEA3_1_SG } & \text { \#QT00064799 } \\ \text { Hs_MAGEA4_1_SG } & \text { \#QT00008862 } \\ \text { Hs_MAGEA5_3_SG } & \text { \#QT01849750 } \\ \text { Hs_MAGEA6_1_SG } & \text { \#QT00059129 } \\ \text { Hs_MAGEA8_1_SG } & \text { \#QT00094668 } \\ \text { Hs_MAGEA9_1_SG } & \text { \#QT00230874 } \\ \text { Hs_MAGEA10_1_SG } & \text { \#QT00005376 } \\ \text { Hs_MAGEA11_1_SG } & \text { \#QT01004094 } \\ \text { Hs_MAGEA12_1_SG } & \text { \#QT00033873 } \\ \text { Hs_SPP1_1_SG } & \text { \#QT01008798 }\end{array}$

All MAGE-A primers used in this study were purchased from QuantiTect. The name and the order number of all primers is shown. MAGE-A, melanoma-associated antigens-A.

An overview on panitumumab treatment efficacy is provided in Fig. 1F. Panitumumab has no relevant cytostatic effect. However, as with the other drugs, there was a significant association between treatment efficacy and time but not concentration (Table VII).

MAGE-A expression. MAGE-A expression analysis showed distinct differences among the cell lines (Fig. 2). Of note, one cell line (PCI-68) showed only a marginal expression of MAGE-A antigens, whereas another cell line (PCI-52) showed a distinct expression of almost all MAGE-A subgroups (10/12). The expression pattern of the other cell lines ranged between that of these cell lines. MAGE-A4 showed the highest expression level of all subgroups, and MAGE-A8 could not be detected. PCI-52 had the highest levels of MAGE-A1 (0.206), 

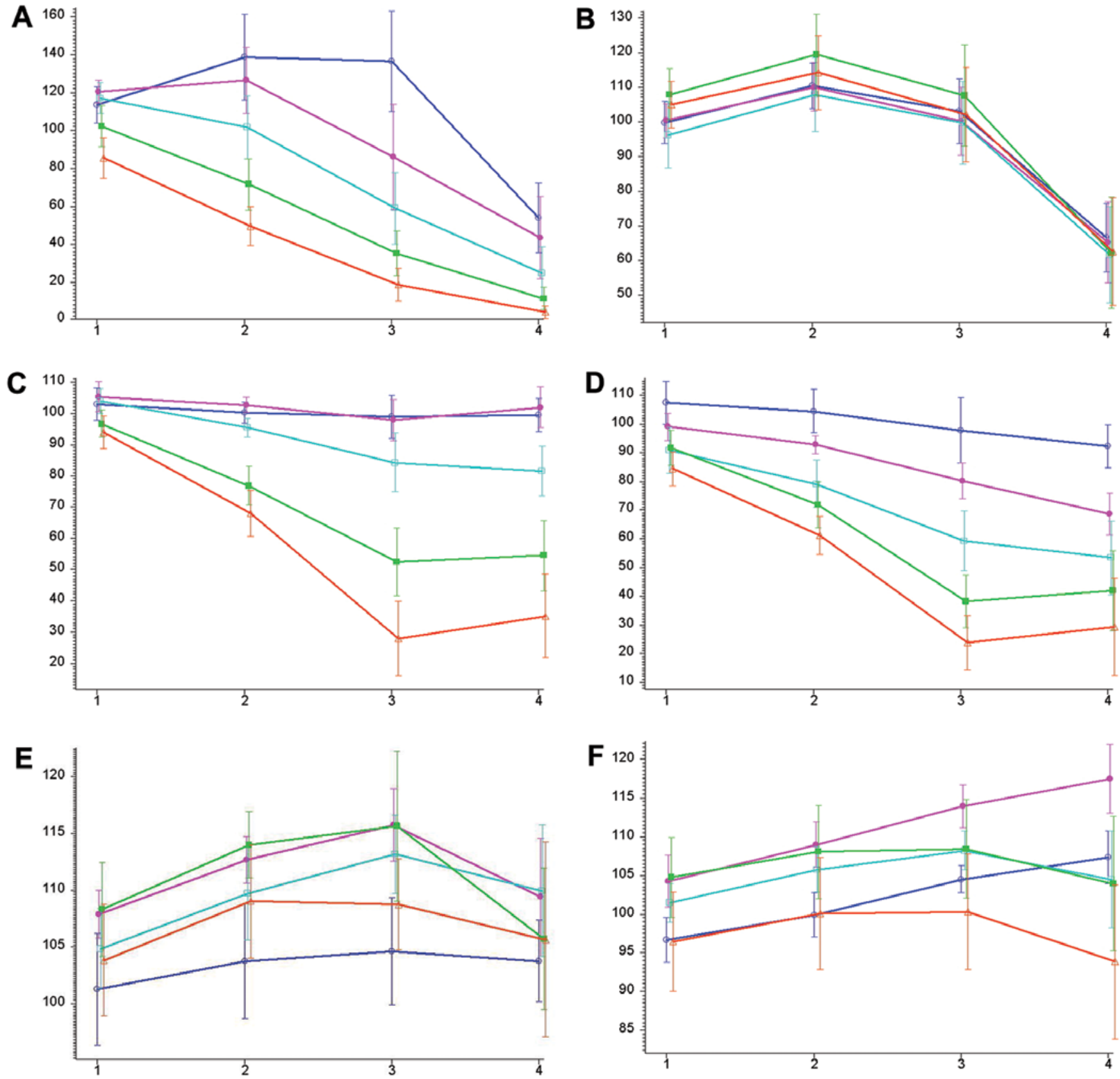

Figure 1. The y-axis represents the viable fraction compared with the control (100). The x-axis shows different time intervals $(1,5 \mathrm{~h} ; 2,10 \mathrm{~h} ; 3,20 \mathrm{~h} ; 4,40 \mathrm{~h})$. The bars indicate the standard deviation of the mean. (A) Cumulative treatment efficacy of cisplatin. The concentrations are as follows: blue, $25 \mu \mathrm{M}$; pink, $50 \mu \mathrm{M}$; turquoise, $100 \mu \mathrm{M}$; green, $200 \mu \mathrm{M}$; red, $400 \mu \mathrm{M}$. (B) Cumulative treatment efficacy of 5-fluorouracil. The concentrations are as follows: blue, $750 \mu \mathrm{M}$; pink, $1.5 \mathrm{mM}$; turquoise, $3 \mathrm{mM}$; green, $6 \mathrm{mM}$; red, $12 \mathrm{mM}$. (C) Cumulative treatment efficacy of paclitaxel. The concentrations are as follows: blue, $1.56 \mathrm{nM}$; pink, $3.12 \mathrm{nM}$; turquoise, $6.25 \mathrm{nM}$; green, $12.5 \mathrm{nM}$; red, $25 \mathrm{nM}$. (D) Cumulative treatment efficacy of docetaxel. The concentrations are as follows: blue, $1.56 \mathrm{nM}$; pink, $3.12 \mathrm{nM}$; turquoise, $6.25 \mathrm{nM}$; green, $12.5 \mathrm{nM}$; red, $25 \mathrm{nM}$. (E) Cumulative treatment efficacy of cetuximab. The concentrations are as follows: blue, $0.01 \mu \mathrm{g} / \mathrm{ml}$; pink, $0.1 \mu \mathrm{g} / \mathrm{ml}$, turquoise, $1 \mu \mathrm{g} / \mathrm{ml}$; green, $10 \mu \mathrm{g} / \mathrm{ml}$; red, $100 \mu \mathrm{g} / \mathrm{ml}$. (F) Cumulative treatment efficacy of panitumumab. The concentrations are as follows: blue, $0.01 \mu \mathrm{g} / \mathrm{ml} ;$ pink, $0.1 \mu \mathrm{g} / \mathrm{ml}$; turquoise, $1 \mu \mathrm{g} / \mathrm{ml}$; green, $10 \mu \mathrm{g} / \mathrm{ml}$; red, $100 \mu \mathrm{g} / \mathrm{ml}$.

-A4 (1.062), -A5 (0.271), -A9 (0.108) and -A11 (0.079). PCI-13 showed the strongest expression of MAGE-A2 (0.242), -A3 (0.643), -A6 (0.641) and A12 (0.969). PCI-1 showed the highest levels of MAGE-A2b (0.822), and PCI-9 had the strongest expression of MAGE-A10 (0.149). With the exception of MAGE-A6, -A8, -A9 and -A10, the expression levels differed significantly among the cell lines (Table VIII).
Factor analysis. The factor analysis suggests the clustering of MAGE-A expression into 4 groups (Table IX). Cluster 1 consists of MAGE-A1, -A4, -A5, -A9 and -A11. Cluster 2 consists of MAGE-A2, -A2b, -A3, -A6 and -A12. MAGE-A8 represents cluster 3, and MAGE-A10 represents cluster 4. Due to the low expression level of the MAGE-A subgroups -A8 and -A10, clusters 3 and 4 were excluded from further analyses. 


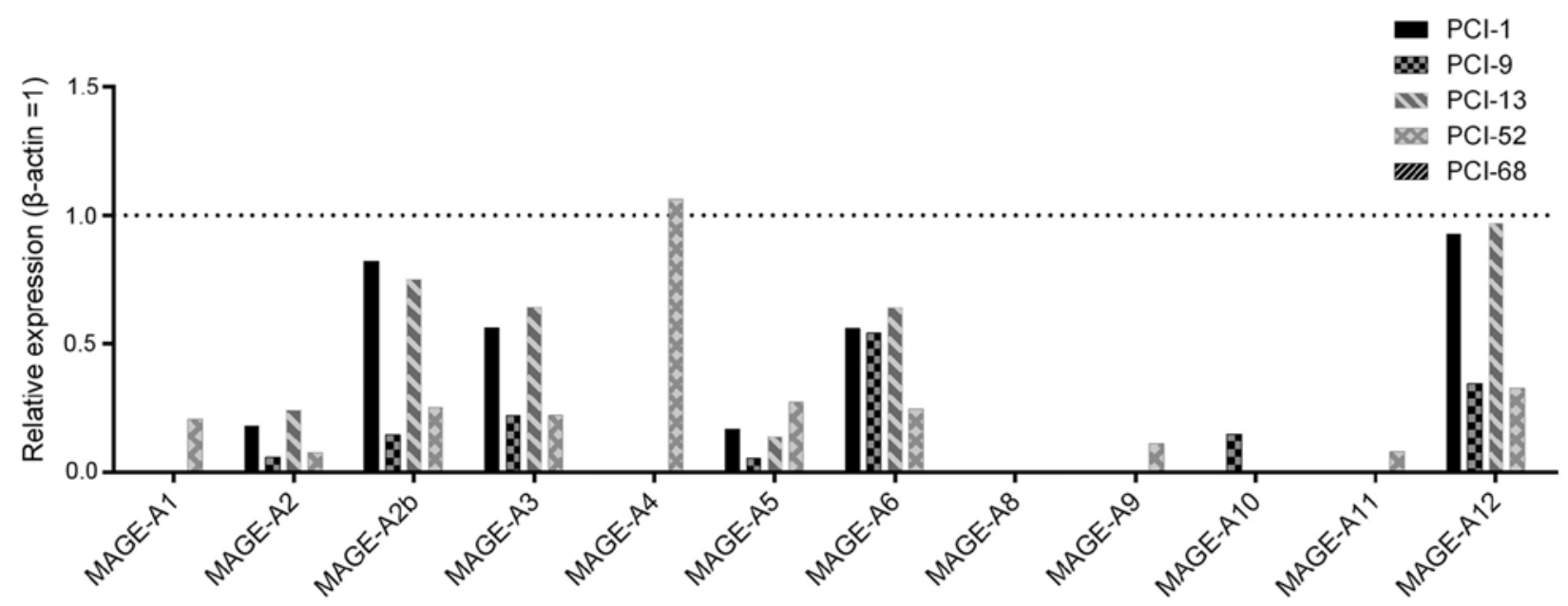

Figure 2. Melanoma-associated antigens-A (MAGE-A) expression profile in the analyzed cell lines. The expression is shown as a relative fraction compared with $\beta$-actin $(=1)$.

Table VII. Association between incubation time or concentration and the treatment efficacy for all drugs tested.

\begin{tabular}{lcc}
\hline Drug & $\begin{array}{c}\text { p-value } \\
\text { (incubation time) }\end{array}$ & $\begin{array}{c}\text { p-value } \\
\text { (concentration) }\end{array}$ \\
\hline Cisplatin & $<0.000005^{\mathrm{a}}$ & 0.19 \\
5-Fluorouracil & $0.00000^{\mathrm{a}}$ & 0.92 \\
Paclitaxel & $<0.000005^{\mathrm{a}}$ & 0.11 \\
Docetaxel & $<0.000005^{\mathrm{a}}$ & 0.098 \\
Cetuximab & $0.00005^{\mathrm{a}}$ & 0.72 \\
Panitumumab & $0.00005^{\mathrm{a}}$ & 0.51 \\
\hline
\end{tabular}

Tested drugs were cisplatin, 5-fluorouracil, paclitaxel, docetaxel, cetuximab and panitumumab. The results of Friedman test are shown. ${ }^{\mathrm{a}} \mathrm{p}<0.001$, indicates extremely significant results.

Due to the suggested clustering, $96.61 \%$ of the variance was represented, and an excellent fitting was achieved.

Correlation of MAGE-A expression and treatment efficacy. In total, 120 experiments (6 drugs, 5 concentrations, 4 time intervals) represent the treatment efficacy of the drugs in each cell line.

First, we analyzed the correlation of total MAGE-A expression level and efficacy of all tested drugs at all concentrations after all time periods. Of note, there was no significant correlation between total MAGE-A expression and treatment efficacy of all tested drugs.

In the next step, we correlated the clustered MAGE-A expression (cluster 1 or 2) with the treatment efficacy of all drugs. High correlations (Rho $\geq 0.7$ ) between MAGE-A expression (group 1 or 2) and lower treatment efficacy were observed in $38.3 \%(46 / 120)$ of the experiments. The analysis revealed a significant correlation between cluster 1 (-A1, -A4, -A5, -A9 and-A11) or cluster 2 (-A2, -A2b, -A 3, -A6 and -A12) expression and several concentrations of cisplatin,5-fluorouracil, docetaxel,
Table VIII. Differences in MAGE-A subgroup expression among the cell lines analyzed by the Friedman test.

\begin{tabular}{ll}
\hline Subgroup & p-value \\
\hline MAGE-A1 & $0.017^{\mathrm{a}}$ \\
MAGE-A2 & $0.024^{\mathrm{a}}$ \\
MAGE-A2b & $0.012^{\mathrm{a}}$ \\
MAGE-A3 & $0.032^{\mathrm{a}}$ \\
MAGE-A4 & $0.016^{\mathrm{a}}$ \\
MAGE-A5 & $0.019^{\mathrm{a}}$ \\
MAGE-A6 & 0.088 \\
MAGE-A8 & 0.22 \\
MAGE-A9 & 0.068 \\
MAGE-A10 & 0.080 \\
MAGE-A11 & $0.025^{\mathrm{a}}$ \\
MAGE-A12 & $0.036^{\mathrm{a}}$
\end{tabular}

MAGE-A, melanoma-associated antigens-A. ${ }^{\mathrm{a}} \mathrm{p}<0.05$ to 0.01 , indicates significant results.

paclitaxel, cetuximab and panitumumab (Table X). Overall, a significant correlation between clustered MAGE-A expression and treatment efficacy was observed in $20.8 \%$ (25/120) of the experiments.

In all 25 cases, a significant correlation Rho was between 0.9 and 1.0, indicating a positive correlation between MAGE-A expression and the RTCA cell index. The RTCA cell index represents the number of viable cells. A higher cell index indicates a minor effective chemotherapeutic treatment. In summary, a higher cluster 1 or 2 MAGE-A expression correlated with a minor efficacy of the tested drugs.

By contrast, a high inverse correlation (Rho $\leq-0.7)$ between MAGE-A expression and treatment efficacy was not observed (data not shown). An inverse correlation (Rho $\leq 0)$ was found in $19.2 \%$ of the cases (23/120). However, none of these correlations were significant (data not shown). 
Table IX. Results of factor analysis.

\begin{tabular}{lccccc}
\hline MAGE & Factor 1 & Factor 2 & Factor 3 & Factor 4 & Commonality \\
\hline A1 & -0.108 & $0.990^{\mathrm{a}}$ & -0.055 & -0.041 & 0.997 \\
A2 & $0.967^{\mathrm{a}}$ & -0.048 & -0.029 & -0.071 & 0.943 \\
A2b & $0.885^{\mathrm{a}}$ & -0.133 & -0.265 & -0.081 & 0.877 \\
A3 & $0.986^{\mathrm{a}}$ & -0.047 & -0.026 & 0.002 & 0.975 \\
A4 & -0.098 & $0.989^{\mathrm{a}}$ & -0.056 & -0.043 & 0.992 \\
A5 & 0.548 & $0.791^{\mathrm{a}}$ & -0.095 & -0.033 & 0.936 \\
A6 & $0.776^{\mathrm{a}}$ & -0.077 & 0.570 & -0.162 & 0.960 \\
A8 & -0.120 & -0.093 & 0.081 & $0.984^{\mathrm{a}}$ & 0.998 \\
A9 & -0.126 & $0.970^{\mathrm{a}}$ & -0.074 & -0.056 & 0.965 \\
A10 & -0.143 & -0.173 & $0.955^{\mathrm{a}}$ & 0.121 & 0.977 \\
A11 & -0.117 & $0.989^{\mathrm{a}}$ & -0.025 & -0.039 & 0.995 \\
A12 & $0.987^{\mathrm{a}}$ & -0.068 & -0.011 & -0.042 & 0.980 \\
Variance & 4.65 & 4.57 & 1.34 & 1.03 & 11.593 \\
Variance (\%) & 38.76 & 38.12 & 11.13 & 8.60 & 96.61 \\
Factor loading & 5 & 5 & 1 & 1 & 12
\end{tabular}

The first factor consists of MAGE-A2, -A2b, -A3, -A6 and A12. The second factor consists of MAGE-A1, -A4, -A5, -A9 and -A11. Factors 3 and 4 consist of MAGE-A10 and -A8, respectively. The 4 factor model represents $96.61 \%$ of the variance. MAGE-A, melanoma-associated antigens-A. 'a' highlights the MAGE-A subgroups being included in the different factors of factor analysis.

Table X. Significant correlations between group 1 or 2 MAGE-A expression and treatment efficacy.

\begin{tabular}{lrrrl}
\hline Drug & Concentration & Time & Rho & p-value \\
\hline Cisplatin & $100 \mu \mathrm{M}$ & $5 \mathrm{~h}$ & 1.0000 & $0.00000^{\mathrm{b}}$ \\
5-Fluorouracil & $750 \mu \mathrm{M}$ & $5 \mathrm{~h}$ & 0.9000 & $0.037^{\mathrm{a}}$ \\
5-Fluorouracil & $3 \mathrm{mM}$ & $5 \mathrm{~h}$ & 0.9000 & $0.037^{\mathrm{a}}$ \\
5-Fluorouracil & $3 \mathrm{mM}$ & $20 \mathrm{~h}$ & 1.0000 & $0.00000^{\mathrm{b}}$ \\
5-Fluorouracil & $12 \mathrm{mM}$ & $20 \mathrm{~h}$ & 1.0000 & $0.00000^{\mathrm{b}}$ \\
5-Fluorouracil & $12 \mathrm{mM}$ & $40 \mathrm{~h}$ & 0.9000 & $0.037^{\mathrm{a}}$ \\
Paclitaxel & $6.25 \mathrm{nM}$ & $20 \mathrm{~h}$ & 0.9000 & $0.037^{\mathrm{a}}$ \\
Paclitaxel & $12.5 \mathrm{nM}$ & $5 \mathrm{~h}$ & 0.9000 & $0.037^{\mathrm{a}}$ \\
Paclitaxel & $25 \mathrm{nM}$ & $20 \mathrm{~h}$ & 1.0000 & $0.00000^{\mathrm{b}}$ \\
Docetaxel & $1.56 \mathrm{nM}$ & $5 \mathrm{~h}$ & 0.9000 & $0.037^{\mathrm{a}}$ \\
Docetaxel & $3.12 \mathrm{nM}$ & $20 \mathrm{~h}$ & 1.0000 & $0.00000^{\mathrm{b}}$ \\
Docetaxel & $3.12 \mathrm{nM}$ & $40 \mathrm{~h}$ & 0.9000 & $0.037^{\mathrm{a}}$ \\
Docetaxel & $6.25 \mathrm{nM}$ & $5 \mathrm{~h}$ & 0.9000 & $0.037^{\mathrm{a}}$ \\
Docetaxel & $12.5 \mathrm{nM}$ & $10 \mathrm{~h}$ & 1.0000 & $0.00000^{\mathrm{b}}$ \\
Cetuximab & $0.01 \mu \mathrm{g} / \mathrm{ml}$ & $5 \mathrm{~h}$ & 0.9000 & $0.037^{\mathrm{a}}$ \\
Cetuximab & $0.01 \mu \mathrm{g} / \mathrm{ml}$ & $20 \mathrm{~h}$ & 0.9000 & $0.037^{\mathrm{a}}$ \\
Cetuximab & $1 \mu \mathrm{g} / \mathrm{ml}$ & $5 \mathrm{~h}$ & 1.0000 & $0.00000^{\mathrm{b}}$ \\
Cetuximab & $10 \mu \mathrm{g} / \mathrm{ml}$ & $40 \mathrm{~h}$ & 1.0000 & $0.00000^{\mathrm{b}}$ \\
Cetuximab & $100 \mu \mathrm{g} / \mathrm{ml}$ & $5 \mathrm{~h}$ & 0.9000 & $0.037^{\mathrm{a}}$ \\
Cetuximab & $100 \mu \mathrm{g} / \mathrm{ml}$ & $20 \mathrm{~h}$ & 0.9000 & $0.037^{\mathrm{a}}$ \\
Cetuximab & $100 \mu \mathrm{g} / \mathrm{ml}$ & $40 \mathrm{~h}$ & 0.9000 & $0.037^{\mathrm{a}}$ \\
Panitumumab & $0.01 \mu \mathrm{g} / \mathrm{ml}$ & $40 \mathrm{~h}$ & 0.9000 & $0.037^{\mathrm{a}}$ \\
Panitumumab & $0.1 \mu \mathrm{g} / \mathrm{ml}$ & $5 \mathrm{~h}$ & 1.0000 & $0.00000^{\mathrm{b}}$ \\
Panitumumab & $1 \mu \mathrm{g} / \mathrm{ml}$ & $5 \mathrm{~h}$ & 0.9000 & $0.037^{\mathrm{a}}$ \\
Panitumumab & $1 \mu \mathrm{g} / \mathrm{ml}$ & $10 \mathrm{~h}$ & 0.9000 & $0.037^{\mathrm{a}}$ \\
\hline
\end{tabular}

Analyzed by the Spearman's rank correlation. MAGE-A, melanomaassociated antigens-A. ${ }^{\mathrm{a}} \mathrm{p}<0.05$ to 0.01 , indicates significant results; ${ }^{\mathrm{b}} \mathrm{p}<0.001$, indicates extremely signficant results.

\section{Discussion}

There is a general agreement that MAGE genes and proteins are often overexpressed in cancer tissues and contribute to the progression of malignancies $(2,17,22)$. In addition, there is growing evidence that MAGE expression is related to a lower efficacy of systemic antitumor treatment and a poorer prognosis of cancer patients. In particular, MAGE-A proteins appear to play a role as regulator of transcription factors, such as p53 $(15,23,24)$. Our group previously described several correlations between MAGE-A expression patterns and treatment efficacy in head and neck cancer $(13,14,20)$. In terms of head and neck cancer, simultaneous nuclear and cytoplasmic expression of MAGE-A proteins is described as an independent marker for poor survival (9). Based on these findings and due to the complexity of different roles of all MAGE-A subgroups, the aim of this study was to investigate the role of total and clustered MAGE-A expression in the context of chemotherapeutic treatment. To the best of our knowledge, this study is the first to examine the correlation of all known MAGE-A subgroups with the impact of antineoplastic treatment.

As expected, the treatment efficacy showed a wide range in the different cell lines. For all drugs, we noticed a significant time-dependent effect. However, treatment with cetuximab and panitumumab did not lead to relevant cytostatic effects. This was previously described by our group (14).

Regarding the MAGE-A levels, our analysis yielded an inhomogenous expression pattern in the different cell lines. One cell line (PCI-52) expressed 10 out of 12 of the investigated MAGE-A subgroups. By contrast, PCI-68 showed only a marginal expression of the MAGE-A subgroups. In our previous studies, we detected MAGE-A8 expression in this cell line panel (14). However, in this study, we did not observe relevant MAGE-A8 expression. This may be explained by the 
fact that another primer set was used in our previous study. The MAGE-A2 gene is found on two different loci on the $\mathrm{X}$ chromosome (MAGE-A2 and MAGE-A2b). Of note, in all cell lines expressing MAGE-A2, we observed higher levels of MAGE-A2b than MAGE-A2. This indicates that PCR-based quantitative MAGE-A expression analysis should always include MAGE-A2 and MAGE-A2b. MAGE-A4 showed the highest levels of all investigated subgroups. With the exception of PCI-68, all of the cell lines expressed multiple MAGE-A subgroups. This phenomenon has been reported in the literature and was described in detail in the study by Ries et al in 2008 (25). Further statistical analysis revealed significantly different expression levels for A1, A2, A2b A3, A4, A5, A11 and $\mathrm{A} 12$, indicating that a diversified panel of cell lines was used.

Since the MAGE-A proteins are considered to be contributors to malignancy, the total amount of protein expression may correlate with a poorer outcome of antineoplastic treatment. To our surprise, total MAGE-A expression was not significantly associated with any of the antineoplastic treatments used in our experiments. This may be explained by complex interactions between pro- and anti-apoptotic functions of different MAGE-A subgroups. Remarkably, the cell line (PCI-52) that was least vulnerable to all agents had the highest cumulative MAGE-A expression. Nevertheless, this cell line was the only one expressing MAGE-A4. Of note, Bandić et al described MAGE-A4 as a positive predictor of survival in women with invasive ductal breast cancer (26). Furthermore, Sakurai et al showed that MAGE-A4 interacts with Myc-interacting zinc finger protein 1 (Miz1), thus leading to apoptosis in a panel of human cancer cell lines (27). On the other hand, PCI-52 is the only cell line expressing relevant amounts of MAGE-A9 and-A11. A negative influence of MAGE-A9 on the prognosis of breast cancer (28), hepatocellular carcinoma (8), renal cell carcinoma (29) and head and neck cancer (12) has been extensively described. MAGE-A11 expression also seems to contribute to malignancy. Xia et al demonstrated that MAGE-A11 distinctly enhances the proliferation of breast cancer cells (30). A study by Lian et al showed that MAGE-A11 expression is a poor prognostic factor for overall survival in breast cancer (31). Taken together, these findings may explain how different MAGE-A subgroups antagonize each other, thus making it impossible to perform a cumulative analysis of all subgroups.

The finding that total MAGE-A expression showed no significant correlation with treatment efficacy led us to perform a cluster analysis of the MAGE-A subgroups. Factor analysis suggested clustering MAGE-A expression into two clusters. The first cluster consists of A1, A4, A5, A9 and A11, whereas A2, A2b, A3, A6, A12 represent the second cluster. MAGE-A 8 and -A10 were excluded due to low expression levels. Of note, a high correlation was observed between clustered expression and minor treatment efficacy in $38.3 \%$ of the experiments (46/120). Remarkably, this finding was significant in $54.3 \%(25 / 46)$ of the cases. This result is quite unexpected as MAGE-A4, -A9 and -A11 were clustered in one group but may have opposite functional roles in terms of apoptosis regulation. Factor analysis revealed a contrast between PCI-13 and PCI-52. These two cell lines showed the highest expression levels of specific MAGE-A subgroups and also had the lowest response to the antineoplastic drugs. Hence, these findings indicate that
MAGE-A expression, in general, is related to a poorer efficacy of antineoplastic treatment. Additional analysis is required to clarify why particular MAGE-A subgroups are clustered together and others are not.

Even if the majority (7/25) of significant correlations between high MAGE-A expression and a lower impact of antineoplastic treatment was found in patients treated with cetuximab, we were unable to draw any specific conclusions for clinical use. This notion is supported by the fact that cetuximab and panitumumab treatment, in general, showed no relevant effect, and our statistical findings regarding the EGFR antibodies should be considered an artifact. In clear contrast, high correlations ( Rho $\leq-0.7$ ) between strong MAGE-A cluster expression and a better treatment efficacy were not observed in any of the cases $(0 / 120)$. Taken together, these results provide further evidence that the co-expression of MAGE-A subgroups contributes to the minor efficacy of antineoplastic treatment.

Since this was a pilot study, there are no direct clinical implications for antineoplastic treatment at this time. Further analysis using tissue samples and an in vitro investigation of the possible interactions among several subgroups are warranted to clarify the role of the MAGE-A expression landscape as a predictor for prognosis in different types of cancer. However, cluster analysis rather than individual subgroup analysis may provide more rapid results and may be less expensive in the future.

\section{Acknowledgements}

Language editing support was provided by the American Journal Experts (AJE).

\section{References}

1. Gupta S, Kong W, Peng Y, Miao Q and Mackillop WJ: Temporal trends in the incidence and survival of cancers of the upper aerodigestive tract in Ontario and the United States. Int J Cancer 125: 2159-2165, 2009.

2. Simpson AJ, Caballero OL, Jungbluth A, Chen YT and Old LJ: Cancer/testis antigens, gametogenesis and cancer. Nat Rev Cancer 5: 615-625, 2005.

3. van der Bruggen $\mathrm{P}$, Traversari C, Chomez $\mathrm{P}$, Lurquin $\mathrm{C}$, De Plaen E, Van den Eynde B, Knuth A and Boon T: A gene encoding an antigen recognized by cytolytic $\mathrm{T}$ lymphocytes on a human melanoma. Science 254: 1643-1647, 1991.

4. Abd-Elsalam EA and Ismaeil NA: Melanoma-associated antigen genes: A new trend to predict the prognosis of breast cancer patients. Med Oncol 31: 285, 2014

5. Li G, Song P and Zhang B: Expression and significance of MAGE genes in human lung cancer. Zhongguo Fei Ai Za Zhi 16: 308-313, 2013 (In Chinese).

6. Dyrskjøt L, Zieger K, Kissow Lildal T, Reinert T, Gruselle O, Coche T, Borre M and Ørntoft TF: Expression of MAGE-A3, NY-ESO-1, LAGE-1 and PRAME in urothelial carcinoma. Br J Cancer 107: 116-122, 2012.

7. Zhang QM, He SJ, Shen N, Luo B, Fan R, Fu J, Luo GR, Zhou SF, Xiao SW and Xie XX: Overexpression of MAGE-D4 in colorectal cancer is a potentially prognostic biomarker and immunotherapy target. Int J Clin Exp Pathol 7: 3918-3927, 2014.

8. Gu X, Fu M, Ge Z, Zhan F, Ding Y, Ni H, Zhang W, Zhu Y, Tang X, Xiong L, et al: High expression of MAGE-A9 correlates with unfavorable survival in hepatocellular carcinoma. Sci Rep 4: 6625, 2014.

9. Laban S, Atanackovic D, Luetkens T, Knecht R, Busch CJ, Freytag M, Spagnoli G, Ritter G, Hoffmann TK, Knuth A, et al: Simultaneous cytoplasmic and nuclear protein expression of melanoma antigen-A family and NY-ESO-1 cancer-testis antigens represents an independent marker for poor survival in head and neck cancer. Int J Cancer 135: 1142-1152, 2014. 
10. Sahin U, Türeci O, Chen YT, Seitz G, Villena-Heinsen C, Old LJ and Pfreundschuh M: Expression of multiple cancer/testis (CT) antigens in breast cancer and melanoma: Basis for polyvalent CT vaccine strategies. Int J Cancer 78: 387-389, 1998.

11. Krauss E, Rauthe S, Gattenlöhner S, Reuther T, Kochel M, Kriegebaum U, Kübler AC and Müller-Richter UD: MAGE-A antigens in lesions of the oral mucosa. Clin Oral Investig 15: 315-320, 2011

12. Han L, Jiang B, Wu H, Zhang S and Lu X: Expression and prognostic value of MAGE-A9 in laryngeal squamous cell carcinoma. Int J Clin Exp Pathol 7: 6734-6742, 2014.

13. Hartmann S, Kriegebaum U, Küchler N, Brands RC, Linz C, Kübler AC and Müller-Richter UD: Correlation of MAGE-A tumor antigens and the efficacy of various chemotherapeutic agents in head and neck carcinoma cells. Clin Oral Investig 18 189-197, 2014.

14. Hartmann S, Kriegebaum U, Küchler N, Lessner G, Brands RC, Linz C, Schneider T, Kübler AC and Müller-Richter UD: Efficacy of cetuximab and panitumumab in oral squamous cell carcinoma cell lines: Prognostic value of MAGE-A subgroups for treatment success. J Craniomaxillofac Surg 41: 623-629, 2013.

15. Monte M, Simonatto M, Peche LY, Bublik DR, Gobessi S, Pierotti MA, Rodolfo M and Schneider C: MAGE-A tumor antigens target p53 transactivation function through histone deacetylase recruitment and confer resistance to chemotherapeutic agents. Proc Natl Acad Sci USA 103: 11160-11165, 2006.

16. Duan Z, Duan Y, Lamendola DE, Yusuf RZ, Naeem R, Penson RT and Seiden MV: Overexpression of MAGE/GAGE genes in paclitaxel/doxorubicin-resistant human cancer cell lines. Clin Cancer Res 9: 2778-2785, 2003.

17. Liu W, Cheng S, Asa SL and Ezzat S: The melanoma-associated antigen A3 mediates fibronectin-controlled cancer progression and metastasis. Cancer Res 68: 8104-8112, 2008.

18. Vansteenkiste J, Zielinski M, Linder A, et al: Adjuvant therapy in stage IB/II non-small cell lung cancer (NSCLC): Final results of a multi-center, double-blind, randomized, placebocontrolled phase II study evaluating the MAGE-A3 cancer immunotherapeutic. EJC Suppl 5: 361, 2007.

19. Heo DS, Snyderman C, Gollin SM, Pan S, Walker E, Deka R, Barnes EL, Johnson JT, Herberman RB and Whiteside TL: Biology, cytogenetics, and sensitivity to immunological effector cells of new head and neck squamous cell carcinoma lines. Cancer Res 49: 5167-5175, 1989.

20. Hartmann S, Seher A, Brands RC, Linz C, Lessner G, Böhm H, Kübler AC and Müller-Richter UD: Influence of epidermal growth factor receptor expression on the cetuximab and panitumumab response rates of head and neck carcinoma cells J Craniomaxillofac Surg 42: 1322-1328, 2014.
21. Wheeler SE, Shi H, Lin F, Dasari S, Bednash J, Thorne S, Watkins S, Joshi R and Thomas SM: Enhancement of head and neck squamous cell carcinoma proliferation, invasion, and metastasis by tumor-associated fibroblasts in preclinical models. Head Neck 36: 385-392, 2014.

22. Yang B, O'Herrin SM, Wu J, Reagan-Shaw S, Ma Y, Bhat KM, Gravekamp C, Setaluri V, Peters N, Hoffmann FM, et al: MAGE-A, mMAGE-b, and MAGE-C proteins form complexes with KAP1 and suppress p53-dependent apoptosis in MAGE-positive cell lines. Cancer Res 67: 9954-9962, 2007.

23. Feng Y, Gao J and Yang M: When MAGE meets RING: Insights into biological functions of MAGE proteins. Protein Cell 2: 7-12, 2011.

24. Marcar L, Maclaine NJ, Hupp TR and Meek DW: MAGE-A cancer/testis antigens inhibit p53 function by blocking its interaction with chromatin. Cancer Res 70: 10362-10370, 2010.

25. Ries J, Vairaktaris E, Mollaoglu N, Wiltfang J, Neukam FW and Nkenke E: Expression of melanoma-associated antigens in oral squamous cell carcinoma. J Oral Pathol Med 37: 88-93, 2008.

26. Bandić D, Juretić A, Sarcević B, Separović V, Kujundzić-Tiljak M, Hudolin T, Spagnoli GC, Cović D and Samija M: Expression and possible prognostic role of MAGE-A4, NY-ESO-1, and HER-2 antigens in women with relapsing invasive ductal breast cancer: Retrospective immunohistochemical study. Croat Med J 47: 32-41, 2006.

27. Sakurai T, Itoh K, Higashitsuji H, Nagao T, Nonoguchi K, Chiba T and Fujita J: A cleaved form of MAGE-A4 binds to Miz-1 and induces apoptosis in human cells. J Biol Chem 279: 15505-15514, 2004.

28. Xu X, Tang X, Lu M, Tang Q, Zhang H, Zhu H, Xu N, Zhang D, Xiong L, Mao Y, et al: Overexpression of MAGE-A9 predicts unfavorable outcome in breast cancer. Exp Mol Pathol 97: 579-584, 2014.

29. Hatiboglu G, Pritsch M, Macher-Goeppinger S, Zöller M, Huber J, Haferkamp A, Pahernik S, Wagener N and Hohenfellner M: Prognostic value of melanoma-associated antigen A9 in renal cell carcinoma. Scand J Urol 47: 311-322, 2013.

30. Xia LP, Xu M, Chen Y and Shao WW: Expression of MAGE-A11 in breast cancer tissues and its effects on the proliferation of breast cancer cells. Mol Med Rep 7: 254-258, 2013.

31. Lian Y, Sang M, Ding C, Zhou X, Fan X, Xu Y, Lü W and Shan B: Expressions of MAGE-A10 and MAGE-A11 in breast cancers and their prognostic significance: A retrospective clinical study. J Cancer Res Clin Oncol 138: 519-527, 2012. 